\title{
The Effects of the Evaluative Content of Premises on the Deductive Reasoning of Psychology Students
}

\author{
Simone Cagnin ${ }^{1, *}$ \\ Orcid.org/0000-0002-8977-3290 \\ Maria Isabel da Silva Leme ${ }^{2}$ \\ Orcid.org/0000-0003-0844-3554 \\ ${ }^{1}$ Universidade do Estado do Rio de Janeiro, Rio de Janeiro, RJ, Brasil \\ ${ }^{2}$ Universidade de São Paulo, São Paulo, SP, Brasil
}

\begin{abstract}
Recent studies in cognitive psychology show evidence of the influence of affective content in statements relating to performance in deductive reasoning tasks. This study investigates the influence of evaluative content related to the education and professional practice of psychologists on the performance of psychology students in tasks involving categorical syllogisms. It also aims to investigate if there is a relationship between the academic integration of these students, who were evaluated by means of the "Questionário de Vivências Acadêmicas reduzido" (QVA-r), and their sensitivity to this content in logical tasks. Participants were 480 psychology students from Brazilian public universities. They were randomly assigned three evaluative content situations: neutral, appreciative and depreciative. Results suggest that depreciative content has a negative effect on the performance of female students. No relevant relationships were found between academic integration (personal, interpersonal, career, studies and institutional) and the number of valid replies to the syllogisms, which points to the effect per se of this content. The results are relevant in an academic context, since the problem-situations experienced by college students may contain evaluative content that can have an influence on deductive reasoning and other processes of a different nature.
\end{abstract}

Keywords: Reasoning, problem-solving, affective content.

\section{Efeitos de Conteúdos Apreciativos e Depreciativos de Premissas no Raciocínio Dedutivo de Estudantes de Psicologia}

\section{Resumo}

Estudos recentes na Psicologia Cognitiva apresentam evidências da influência dos conteúdos afetivos contidos em enunciados de problemas no desempenho em tarefas de raciocínio dedutivo. Este estudo investiga a influência de conteúdos valorativos relacionados à formação e à atuação profissional dos psicólogos no desempenho de estudantes de Psicologia em tarefas que envolvem silogismos categóricos.

* Mailing address: Av. São Francisco Xavier, 524, 10 andar, salas 10022/ 10028, Maracanã, Rio de Janeiro, RJ, Brazil 20550-900. Phone: 2334 0234. E-mail: simcagnin@gmail.com

Acknowledgement: The authors would like to thank José Augusto Evangelho Hernandez, teacher at Rio de Janeiro State University, for his assistance in data analyses. 
Visa ainda investigar se a integração acadêmica desses estudantes, avaliada através do Questionário de Vivências Acadêmicas reduzido (QVA-r), teve relação com a sensibilidade a estes conteúdos nas tarefas lógicas. Participaram da pesquisa 480 estudantes de cursos de Psicologia de universidades públicas brasileiras, sendo estes divididos, aleatoriamente, em três condições de conteúdo valorativo: neutro, apreciativo e depreciativo. Os resultados obtidos sugerem um efeito negativo dos conteúdos depreciativos no desempenho das estudantes do sexo feminino. Não foram encontradas relações relevantes entre as dimensões da integração acadêmica (pessoal, interpessoal, carreira, estudo e institucional) e o número de respostas válidas nos silogismos, o que aponta para um efeito per se desses conteúdos. Acredita-se que os resultados possam ter relevância para o contexto acadêmico, pois as situações-problema vivenciadas pelos alunos na universidade podem revestir-se de conteúdos valorativos que podem ter influência no raciocínio dedutivo, bem como em outros processos de diferentes naturezas.

Palavras-chave: Raciocínio, resolução de problemas, conteúdos afetivos.

\section{Efectos de Contenido Evaluativo de las Premisas en el Razonamiento Deductivo de los Estudiantes de Psicología}

\section{Resumen}

Estudios recientes en la Psicología Cognitiva han mostrado evidencia de la influencia del contenido afectivo que recubre los problemas de razonamiento lógico. Este estudio tiene como objetivo investigar la influencia de contenido evaluativo sobre la formación y sobre la práctica profesional de psicólogos en el rendimiento de los estudiantes de psicología en las tareas lógicas que implican silogismos categóricos. También busca investigar si la integración académica de los estudiantes, determinada por el "Questionário de Vivências Acadêmicas reduzido" (QVA-r), estaba relacionado con la sensibilidad a estos contenidos en tareas lógicas. 480 estudiantes de Psicología de universidades públicas brasileñas participaron del estudio y fueron divididos aleatoriamente en tres condiciones de evaluación, contenido neutral, apreciativo y despectivo. Los resultados sugieren un efecto negativo de los contenidos despectivos en las mujeres. No hubo relaciones significativas entre las dimensiones de la integración académica y las respuestas válidas en los silogismos, lo que apunta a un efecto per se de contenido evaluativo. Los hallazgos podrían tener especial importancia para el contexto escolar, en la medida en que las situaciones problemáticas enfrentadas por los estudiantes universitarios en su rutina academica pueden ser de contenido evaluativo que pueden influenciar el desempeño en el razonamiento deductivo y en otros procesos de naturalezas diferentes.

Palabras clave: Razonamiento, resolución de problemas, contenidos afectivos.

Evidence from studies into human reasoning suggests that the contents of propositions may significantly influence how people reason, such as when the task involves familiar content, for example. These studies show that both inductive reasoning and hypothetical-deductive reasoning are subject to the influence of the content of both propositions and premises (Tversky \& Kahneman, 1983). They also show that logical deductions frequently evaluate the consequences of applying rules, laws, and moral principles, and this ability may vary in individuals depend- ing on their intelligence and the capacity of their work memory (Johnson-Laird, Khemlani, \& Goodwin, 2015).

Despite the multiplicity of lines of research found in the area, a significant number of these investigations are based on an information-processing approach, which investigates the influence of the content of neutral semantic statements in solving different types of problem, including logical problems that involve deductive reasoning, in other words, containing content whose problem statements have no affective tonality 
(e.g. De Neys, 2012). Lefford (1946) was one of the first researchers to prove that, in solving syllogisms with negative affective content, individuals committed more logical errors than with neutral statements; this was confirmed in subsequent studies (Blanchette \& Leese, 2011; Jung, Wranke, Hamburger, \& Knauff, 2014).

A growing number of studies (De Jong \& Vroling, 2014; De Neys, 2012, 2014) have been pointing to the influence of individuals' beliefs and expectations on human deductive reasoning. The findings of many of these studies have shown that when the content of syllogisms and logical tasks coincide with the beliefs and everyday knowledge of individuals, there is an improvement in performing these tasks. In contrast, when there is a conflict between beliefs, expectations and logic, performance is usually negatively affected, especially in logically invalid forms of syllogisms, in other words, in "affirming the consequent" and "denying the antecedent". There are also studies that emphasize the influence of affective states on reasoning, including also mood states activated by experimental stimuli and/or more specific emotions, as well as the influence per $s e$ of the tonality of the content of the statements of problems that involve deductive reasoning (Blanchette \& Campbell, 2012; Blanchette \& Leese, 2011; Blanchette \& Richards, 2010). The content of the statements of the premises in these researches is often manipulated according to the valence of the affective state evoked in the individuals (positive, negative or neutral). Since affective similarity facilitates performance, the effects of the congruence and incongruence that exists between affective states and the premises' negative or positive content are also usually evaluated in this context.

Although there is evidence showing the negative effect of negative affective states and content on deductive reasoning (Blanchette \& Leese, 2011; Jung et al., 2014; Lefford, 1946), there are also studies that indicate that positive affective states may negatively influence performance in logical tasks involving syllogisms (Melton, 1995), because of their interference in the more analytical processing required by the application of logical rules. On the other hand, there are studies that point to the beneficial effects of positive affective states and content in certain types of formal tasks, such as those involving syllogisms, or informal reasoning tasks (Blanchette \& Caparos, 2013; Eliades, Mansell, Stewart, \& Blanchette, 2012).

These results challenge the prevailing idea that negative affective content always has a negative influence on performance in logical tasks. As the above authors emphasize, in some circumstances this content may favor logical performance, especially when the valence of the affective tonality of the content is compatible with the valence of the affective state of the individual. This is because, as the studies of Blanchette and Caparos (2013) and Blanchette, Lindsay and Davies (2014) point out, even though the content may be negative, its relevance and utility may favor the performance of individuals who feel they identify with it.

As one of the models most widely-used for explaining the impact of affective content on reasoning postulates, there are two systems that can be used in tasks that require logical reasoning, as Kahneman (2003) proposes, using the terms "System 1" and "System 2" that were initially mentioned by Stanovich and West (2002). The so-called "System 1" involves heuristic, implicit, rapid, and widely contextualized processes based on prior knowledge. "System 2" involves analytical, explicit, slow, rules-based processes that require the allocation of cognitive resources and overload on the working memory. Different studies, such as those by Blanchette and Amato (2014), point to the dominance of implicit heuristic processes in problem situations where there is a confrontation between emotion and reason, with the consequent reduction of the more analytical and explicit processing required for logical tasks that demand, on the one hand, attention and cognitive overload, and on the other, the containment of automatic responses and the interference of the beliefs and knowledge of those solving the task. In this perspective, people in general tend to make judgments 
and reason logically based on quick, intuitive impressions, rather than doing so deliberately and analytically (Evans, 2008; Kahneman, 2003; Kahneman \& Frederick, 2005).

Blanchette (2014) observes that many study results are consistent with the literature about attention and memory, since information of an affective nature attracts more attention, and information that is congruent with the affective state becomes more accessible in the long-term memory. According to this author, emotion supplies relevant information to be applied in reasoning tasks, including deductive reasoning, changes how information is processed and influences what additional information can be used in these tasks. In this regard, Blanchette and Richards (2010) believe that affective states can change the semantic context constructed in inference processes, thus boosting the effects of affectivity on deductive reasoning, which seems to corroborate the hypothesis that affectivity can serve as a "source of information" and might explain, in part, how affective states affect deductive reasoning. Nevertheless, this semantic priming can vary depending on contextual factors, such as the nature of the task and the complexity of the information. Affective processes, however, go beyond semantic processing, because they involve qualitatively different non-informational processes, in other words, non-cognitive processes, or as Nicolle and Goel (2014) prefer, processes directly linked to "emotion as emotion". Among the non-informational aspects of emotions are physiological changes; according to Blanchette (2014), this would be the second route by which affectivity affects reasoning, including deductive reasoning.

Perception of the conflict between logic and belief is usually implicit and often evaluated by way of measures related to non-informational aspects of emotion, such as those referred to above. A type of diffuse "logical feeling", which is expressed in individuals by way of a sensation of "discomfort" and uncertainty as to their responses, seems to arise when there is conflict between beliefs and the logical validity of the task. In fact, Boden and Barenbaum (2010) em- phasize the close relationship between emotions and beliefs, and propose that there exists a sort of "feedback loop" between them. In a problem situation, when there is uncertainty and ambiguity, the chance increases of personal beliefs and expectations interfering in the solution, rather than abstract knowledge and logical rules.

In some studies in the area we see stories with propositions that have affective or neutral content being presented before tasks that involve the solving of syllogisms with affective or neutral content (Gangemi, Mancini, \& JohnsonLaird, 2013). In other studies, participants are instructed to answer questions about the emotions experienced in a traumatic situation (e.g. in the face of a terrorist attack) prior to the tasks with syllogisms per se (Blanchette, Richards, Melnyk, \& Lavda, 2007). So the use of stories prior to the syllogisms or the instruction to remember experiences related to traumatic situations before the presentation of syllogisms seem to "boost" the effects of the affective content of the latter, by favoring a same affective tonality context. In this study, with the aim of "boosting" any possible affective priming effects, stories were presented prior to the tasks with syllogisms that, in turn, dealt with the education and professional work of psychologists in the evaluative content groups, and with the distribution of psychology courses in Brazil in the neutral content group.

As for any special effects of variables such as gender and experiences on performance in reasoning tasks involving affective content, Brody and Hall (2008) point out that research that focuses on the differences between men and women found that they are influenced by social, cultural, cognitive, biological, and behavioral variables. The recurring stereotype is that women are more emotional than men, and that they express and verbalize more emotions than men, but empirical data suggest that the issue is much more complex than this. With regard to regulating the emotions, some studies observe that women tend to use interpersonal strategies in a more prevalent way, as well as rumination strategies that focus the attention more on negative feelings (Nolen-Hoeksema \& Jackson, 2001), which might partly explain women's greater sen- 
sitivity to negative affective content. Personality aspects and the degree of motivation, however, may hinder or facilitate this regulation, thus adding to the possible effects of the differences between the sexes. Because of these results, one of the hypotheses of this research is that female students will be more sensitive to this content, especially to depreciative evaluative content. This study aims to clarify, in part, these effects in view of the suggestions underlying the results found in preliminary studies, in which women presented more logical errors when faced with this type of content, but whose performance was equivalent to that of men when faced with neutral content.

Finally, the importance of experiences needs to be analyzed, like the participants' academic integration and its possible relationship with their performance in tasks involving categorical syllogisms that either appreciate or depreciate their education and professional activities. Modern research has sought to investigate the academic satisfaction and/or experiences of university students (Granado, Santos, Almeida, Soares, \& Guisande, 2005; Igue, Bariani, \& Milanesi, 2008; Lamas, Ambiel, \& Silva, 2014; Sarriera, Paradiso, Shutz, \& Howes, 2012; Schleigh, 2006; Schleigh, Polydoro, \& Santos, 2006; Soares et al., 2014; Tessema, Ready, \& $\mathrm{Yu}, 2012$ ). In fact, some studies (Igue et al., 2008; Lamas et al., 2014; Sarriera et al., 2012; Schleigh, 2006) used the QVA-r with the aim of assessing the academic integration of university students in this context, often relating it to other aspects of university and/or professional life, among other aspects. As Granado (2004) indicates, the 'university integration' construct is a multifaceted phenomenon that integrates the influence of personal characteristics, expectations and abilities with the influence of institutional and contextual characteristics and the interactions that occur in the university.

The results of these studies generally indicate that the career dimension in comparison with the personal, interpersonal, study and institutional dimensions, which go to make up the 55 items of QVA-r, gives higher averages than the others, suggesting that university students seem to have, in general, a positive perception of their choice of course and their professional prospects. On the other hand, the lower mean figure that is normally found in the personal dimension might indicate a more negative perception of aspects related to physical and psychological wellbeing, which could also suggest a perception of themselves as having less emotional stability and a low level of confidence and self-concept (Schleigh, 2006).

It should be pointed out that the application of the QVA-r in our study aimed at clarifying, on the one hand, the possible relationships that exist between subjective aspects of university students, such as anxiety, mood swings, professional expectations and engagement with the chosen course, and greater sensitivity to the evaluative content of syllogisms related to their professional education and work. So our objective was not to investigate academic integration per se, as the above-mentioned studies propose, but rather to explore if there are any relationships between academic integration and performance in logical tasks that involve syllogisms that have content related to the education and the professional activities of the students.

In short, the study aims to investigate the influence of the evaluative content of syllogisms on the performance of university students. This content makes positive or negative value judgment regarding the future profession of these students and also, whether these correspond to their expectations and beliefs with regard to their course and profession, thereby reinforcing the impact they may have on this performance. Differences in performance between the sexes will be considered here, as will the possible relationships between the participants' academic integration and their greater sensitivity to this content.

\section{Method}

The research reported here comprises two specifically-designed, complementary, transversal and experimental studies: 3 (groups) vs. 2 (sexes) and 3 (groups) vs. 4 (types of syllogism), the dependent variables being the performance in 
tasks with syllogisms and in the questionnaires applied, respectively. The relationships between performance in the tasks with syllogisms and academic integration and their dimensions as measured by the QVA-r were also explored.

\section{Participants}

The final convenience sample consisted of 480 university students (318 females and 162 males), with an average age of 22.4 years $(S D=$ 5.44), and ranging from 17 to 49 years old. They are all studying on psychology courses in seven Brazilian public universities located in six states and three Brazilian regions (southeast, south and northeast). There was no significant difference in the distribution of the participants in the groups $\left[X^{2}(2)=0.042 ; p>.05\right]$ and there was no significant difference between the means of the responses in the syllogism tasks by region $[F(2$, $\left.477)=2.77 ; p>.05 ; \boldsymbol{\eta}^{2}=0.12\right]$.

With the intention of equating the sample, 31 female students were randomly excluded, although proportionality was maintained within each group. In accordance with previously established criterion, eight participants (seven women and one man) were also excluded, since they left at least one answer blank on the QVA-r and/or in the task with syllogisms. There was no significant difference $[t(509)=0.01 ; p>.05 ; d=0.007]$ between the mean of the randomly excluded participants $(M=6.41 ; S D=1.47)$ and that of the final sample ( $M=6.42 ; S D=1.42)$ in performing the tasks with syllogisms, neither was there any significant difference between the means $(M=3.62$; $S D=0.32 ; M=3.53 ; S D=0.42$, respectively) in the replies in the QVA-r $[t(509)=1.2 ; p>.05$; $d=0.24]$.

\section{Instruments}

As far as concerns the evaluation of the effects of the evaluative content in the syllogistic reasoning of the students, the objective of this study, eight syllogisms were constructed, two in each form of syllogism (Modus Ponens, Modus Tollens, Affirming the Consequent and Denying the Antecedent). Of these eight syllogisms, four contained premises with female names and four with male names. This is an example of a syllogism that was presented "Every psychologist values ethics in his work. Joaquim does not value ethics in his work. So Joaquim is not a psychologist." The syllogism statements and the stories that preceded them were constructed in an attempt to equate the words they had in common between them, the length of the sentences, the contraposition of ideas bearing in mind the adjectives used and their appreciative and depreciative impact. In this context, the degrees of difficulty of the tasks were also equated.

Before presenting the task with the syllogisms, stories were presented that dealt with the percentage and distribution of psychology courses in Brazil (a neutral story, presented to the neutral content group) or on the education and work of psychologists. In this latter case, the stories valued this education and activity in the groups with appreciative content, or depreciated this education and activity in the groups with depreciative content. The objective behind presenting stories before the syllogisms was to boost the effects of the evaluative tonality of the content of the premises.

Four questions, which were evaluated using a four-point Likert scale, which ranged from the "none" option to the "very extensive" option, were applied in the groups. The questions were used to obtain information about the students' experience in solving syllogisms, the degree of difficulty they encountered in carrying out the tasks, the participants' agreement / disagreement with the evaluations contained in the statements, and whether they felt affectively involved by the content of the statements. The participants' opinion on the task was elicited by way of an open and optional question.

Another instrument used was the Academic Experience Questionnaire (QVA-r), reduced version, which was presented to all participants before reading the stories and the task with syllogisms. The purpose behind applying this questionnaire was to investigate if the academic integration of the university students might be related to the valid responses in the tasks with 
syllogisms. This questionnaire has its origin in the Portuguese version that was put together and validated by Almeida, Soares, and Ferreira (2001), and adapted and validated for the Brazilian context by Granado et al. (2005); Santos, Noronha, Amaro, and Villar (2005). It has a significant psychometric quality, in particular, it has good internal consistency $(\alpha=0.88)$, and is suitable for use in a Brazilian context. The QVA$r$ is a self-reporting instrument organized as a 5-point Likert scale $(1=$ nothing to do with me, and $5=$ everything to do with me). The Brazilian version has 55 items divided into 5 dimensions; personal (14 items), interpersonal (12 items), career (12 items), study (9 items) and institutional ( 8 items). The personal dimension evaluates the perception of psychological and physical wellbeing $(\alpha=0.84)$. The interpersonal dimension $(\alpha=0.82)$ evaluates the relationship with colleagues and the stability of these relationships. The career dimension $(\alpha=0.86)$ evaluates the perception of the personal competences associated with the chosen career and professional prospects, while the study dimension $(\alpha=0.78)$ evaluates study routines, and the planning and execution of school tasks. The institutional dimension $(\alpha=0.77)$ evaluates the educational institution, its infrastructure and services (Granado, 2004). All participants were asked an open question with regard to their comments about university life after the QVA-r presentation.

\section{Procedure}

After being approved by the Ethics Committee (Opinion 015-2013), permission was requested to carry out the research in public universities and with their teachers. Students were then asked to participate and to respond individually to the material, which was applied in their classrooms. Participation was voluntary and the Term of Free and Informed Consent was distributed and signed by all, with the guarantee that ethical research procedures would be observed.

Participants responded individually to the material described above in the following order: Academic Experience Questionnaire, reading of stories, task with syllogisms and the questionnaire about the task.

After completing the cover page with information about the gender, age, period and university, participants were initially presented with the Academic Experience Questionnaire (QVA-r), which was followed by an open and optional question on their opinion about university life. Then the neutral, appreciative and depreciative content groups were presented with stories that had neutral, appreciative and depreciative affective content, respectively. After reading the stories, the tasks with the four types of syllogism (Modus Ponens, Modus Tollens, Affirming the Consequent and Denying the Antecedent) were randomly presented in each content group to three different groups of students (tasks with syllogisms with neutral, appreciative and derogatory content). After reading each syllogism, participants were asked to indicate whether or not the conclusions would logically derive from the statements made in the first premise, or not. Finally, they were presented with four brief questions that dealt with: their opinion on the difficulty of the task, their experience with syllogisms, their agreement or disagreement with the content of the syllogisms presented, and their affective involvement with the content of the statements of the task.

The exercise lasted 30 minutes, on average, and, at the end they were thanked for their participation and a commitment to publicize the results was made.

It should be noted that the material was pretested with 30 participants, in order to adjust the instruments and procedures, if necessary, especially with regard to their opinion on the affective evaluative content of the stories and on their comprehension of and the relevance of the task with syllogisms. In the open questionnaire that was applied there was consensus on the affective content of the syllogisms and the stories (neutral, appreciative and depreciative) and on the fact that the task was easy to understand and of academic relevance. This initial sampling questionnaire was reduced to four brief questions that were evaluated on a 4-point Likert scale that 
has already been reported on in the item "Instruments". There was no significant difference $[t$ (508) $=1.34 ; p>.05 ; d=0.12$ ] between the means of the logically valid responses to the syllogisms in the Pilot Study $(M=6.24 ; S D=1.5)$ and in the reported research $(M=6.42 ; S D=1.42)$.

The results were analyzed using the SPSS20 statistical package and the Variance Analysis, Tukey (post hoc), Student's T, Cohen's, the partial Eta squared (post hoc), Chi-Squared, and Pearson's Correlation statistical tests.

\section{Results}

\section{Results Obtained in the Tasks with syllogisms}

The results referring to the three groups of participants are shown in Table 1.

Table 1

Descriptive Statistics by Sex and the Total Number of Participants in the Syllogism Tasks in the Three Evaluative Content Situations

\begin{tabular}{lrccccccccccccc}
\hline & \multicolumn{4}{c}{ Neutral } & \multicolumn{1}{c}{ Appreciative } & \multicolumn{2}{c}{ Depreciative } & \multicolumn{2}{c}{ Total } \\
& \multicolumn{1}{c}{$N$} & $M$ & $S D$ & $N$ & $M$ & $S D$ & $N$ & $M$ & $S D$ & $N$ & $M$ & $S D$ & $I 95$ \\
\hline Females & 107 & 6.46 & 1.35 & 106 & 6.41 & 1.44 & 105 & 5.81 & 1.53 & 318 & 6.23 & 1.46 & $6.07-6.39$ \\
Males & 53 & 6.76 & 1.28 & 55 & 6.87 & 1.17 & 54 & 6.72 & 1.34 & 162 & 6.78 & 1.26 & $6.69-6.98$ \\
Total & 160 & 6.56 & 1.33 & 161 & 6.57 & 1.37 & 159 & 6.12 & 1.52 & 480 & 6.42 & 1.42 & $6.29-6.54$ \\
\hline
\end{tabular}

The results were initially analyzed in an ANOVA $3 \times 2$, when a main group effect $[F(2$, $\left.477)=3.24 ; p<.05 ; \boldsymbol{\eta}^{2}=0.13\right]$ and also sex $[F$ $\left.(1,478)=17.31 ; p<.001 ; \boldsymbol{\eta}^{2}=0.35\right]$ were found, but there was no interactive effect between the "group" and "sex" variables $[F(2,477)=1.89$; $\left.p>.05 ; \boldsymbol{\eta}^{2}=0.008\right]$. In post hoc comparisons (Tukey test), significant differences were obtained $(p<.05)$ between the means of the depreciative and neutral content groups and between the means of the depreciative and appreciative content groups.

On the one hand it was noted that the group with depreciative content had means $(M=6.12 ; S D=1.52)$ for valid replies that were significantly smaller $[F(2,477)=5.29 ; p<$ $.05]$ than the means of the groups with neutral $(M=6.56 ; S D=1.33)$ and appreciative $(M=6.57$; $S D=1.37)$ content, although there were no significant differences $(p>.05)$ between the results of the groups with appreciative and neutral content. When the "sex" variable was taken into account, significant differences were observed in the performance of women and men in the syllogisms with depreciative content $[t$
$(157)=3.72 ; p<.001]$, since the women had a mean $(M=5.81 ; S D=1.53)$ that was significantly smaller in valid responses than that of the men $(M=6.72 ; S D=1.34)$, in contrast with the mean for the women and men in the neutral content group ( $M=6.46 ; S D=1.35 ; M=6.76 ; S D=1.28$, respectively), where there were no significant differences $[t(158)=1.3 ; p>.05]$. As far as concerns the appreciative content, no significant differences were found $[t(159)=2.03 ; p>.05]$ between the means for the females and the males $(M=6.41 ; S D=1.44 ; M=6.87 ; S D=1.17$, respectively).

In order to calculate the size of the effect for comparing the means of the women and men in the evaluative content groups, the Cohen test was applied, considering the homogeneity of the sample, and $d=0.64$ was obtained, in comparison with the means of the depreciative content group, in other words, an effect that was considered to be moderately strong. But when we compare the performance of women and men in groups with neutral $(d=0.22)$ and appreciative $(d=0.3)$ content, the size of the effect proves to be weak. 
As far as the influence of the types of syllogism is concerned, the biggest mean of valid responses was found in the "Modus Ponens" $(M=1.81 ; S D=0.5)$ and the smallest in the "Modus Tollens" $(M=1.37 ; S D=0.78)$. But when the results are compared in the three evaluative content situations we find a main group effect, with significant differences between the means of valid responses obtained in the "Modus Ponens" $\left[F(2,477)=6.38 ; p<.005 ; \boldsymbol{\eta}^{2}=0.26\right]$ and in "Denying the Antecedent" $[F(2,477)=4.64 ; p<.05$; $\left.\boldsymbol{\eta}^{2}=0.019\right]$, but not in the "Modus Tollens" $[F(2$, $\left.477)=0.77 ; p>.05 ; \boldsymbol{\eta}^{2}=0.03\right]$ and in "Affirming the Consequent" $[F(2,477)=1.47 ; p>.05$; $\left.\boldsymbol{\eta}^{2}=0.06\right]$. In "Modus Ponens", with the Tukey correction these differences appeared between the means $(M=1.88 ; S D=0.38 ; M=1.7 ; S D=0.65$, respectively) of valid responses from the neutral and depreciative content groups $(p<.005)$ and between the means $(M=1.86 ; S D=0.42$; $M=1.7 ; S D=0.65$, respectively) of the appreciative and depreciative groups $(p<0.05)$. In the "Denying the Antecedent" type, however, as happened with the "Modus Ponens", these differences only appeared between the means of valid responses of the neutral content $(M=1.66$;
$S D=0.62)$ and depreciative content $(M=1.48$; $D P=0.78)$ groups and the means of the appreciative content $(M=1.69 ; S D=0.58)$ and depreciative content $(M=1.48 ; S D=0.78)$ groups.

With regard to the sex of the participants, we found significant differences between the means of women $(M=1.53 ; S D=0.72)$ and men $(M=1.77 ; S D=0.54)$ in 'Denying the Antecedent" $[t(478)=3.70 ; p<.001 ; d=0.38]$, but not in the other types of syllogism. When only the means of the women's valid responses are compared in the three evaluative content situations in each type of syllogism, we found significant differences in the means of the "Modus Ponens" [F (2, $\left.315)=4.52 ; p<.05 ; \boldsymbol{\eta}^{2}=0.028\right]$ and in the means of "Denying the Antecedent" $[F(2,315)=3.41$; $\left.p<.05 ; \boldsymbol{\eta}^{2}=0.021\right]$. In contrast, the men showed no significant differences between themselves in these means $\left[F(2,159)=2.23 ; p>.05 ; \boldsymbol{\eta}^{2}=0.027\right.$; $F(2,159)=2.51 ; p>.05 ; \boldsymbol{\eta}^{2}=0.031$, respectively].

\section{Results obtained with the Questionário de Vivências Acadêmicas (QVA-r)}

The results obtained with the QVA-r by psychology students can be found in Table 2 .

Table 2

Mean and Standard Deviation of the Participants in the Dimensions and Total QVA-r

\begin{tabular}{|c|c|c|c|c|c|c|c|c|c|c|}
\hline \multicolumn{11}{|c|}{ Dimensions } \\
\hline Personal & \multicolumn{2}{|c|}{ Interpersonal } & \multicolumn{2}{|c|}{ Career } & \multicolumn{2}{|c|}{ Study } & \multicolumn{2}{|c|}{ Institutional } & \multicolumn{2}{|c|}{ Total QVA-1 } \\
\hline$M \quad S D$ & $M$ & $S D$ & $M$ & $S D$ & $M$ & $S D$ & $M$ & $S D$ & $M$ & $S D$ \\
\hline 3.210 .56 & 3.62 & 0.70 & 3.83 & 0.56 & 3.29 & 0.68 & 3.69 & 0.65 & 3.53 & 0.42 \\
\hline
\end{tabular}

We noted scores over 3 , the average of the scale, in all the dimensions and in the total QVA-r, which suggests that the students are satisfactorily integrated academically.

The differences between the sexes in the QVA-r scores are shown in Table 3 below.

As can be seen, the scores over 3 in the scale dimensions and in the total QVA-r suggest that both sexes are satisfactorily integrated academically. The women had significantly higher means than men in the interpersonal dimensions $[t(478)$
$=2.0 ; p>.05]$, career $[t(478)=2.31 ; p<.05]$ and study $[t(478)=2.14 ; p<.05]$ and lower in the personal dimension $[t(478)=2.0 ; p<.05]$, but the size of the effect was small in these comparisons $(d=0.21 ; d=0.21 ; d=0.2 ; d=0.18$, respectively). In the institutional dimension $[t(478)=$ $1.01 ; p>.05 ; d=.09]$, on the other hand, and in the total QVA-r score $[t(478)=1.88 ; p>.05 ; d$ $=0.19]$ there were no significant differences between the sexes. In the personal dimension, the significantly lower mean scores for women in- 
Table 3

Descriptive Statistics, T-Test and Size of the Effect for Mean Scores by Sex in the Dimensions and Total QVA-r

\begin{tabular}{lcccccccrr}
\hline \multirow{2}{*}{ Dimensions } & \multicolumn{9}{c}{ Sex } \\
& \multicolumn{2}{c}{ Female } & \multicolumn{2}{c}{ Male } & & & & \\
\cline { 2 - 7 } & $M$ & $S D$ & $M$ & $S D$ & $t$ & $g l$ & $p$ & $d$ \\
\hline Personal & 3.18 & 0.53 & 3.28 & 0.59 & 2.00 & 478 & .05 & 0.18 \\
Interpersonal & 3.67 & 0.69 & 3.52 & 0.71 & 2.32 & 478 & .02 & 0.21 \\
Career & 3.87 & 0.53 & 3.75 & 0.60 & 2.31 & 478 & .02 & 0.21 \\
Study & 3.34 & 0.66 & 3.20 & 0.71 & 2.14 & 478 & .03 & 0.20 \\
Institutional & 3.71 & 0.62 & 3.65 & 0.71 & 1.01 & 478 & .31 & 0.09 \\
Total QVA-r & 3.56 & 0.40 & 3.48 & 0.44 & 1.88 & 478 & .06 & 0.19 \\
\hline
\end{tabular}

clude items related to "mood swings", "tiredness and drowsiness", "moments of distress" and "physical weakness" that are negative indices here, the valences of which were inverted in the statistical analysis, thus signaling greater mood swings, greater tiredness, etc.

In the evaluative content groups there were no significant differences between the means in the personal $\left[F(2,477)=0.27 ; p>.05 ; \boldsymbol{\eta}^{2}=\right.$ $0.0001]$, interpersonal $[F(2,477)=0.062 ; p>.05$; $\left.\boldsymbol{\eta}^{2}=0,0001\right]$, career $[F(2,477)=1.07 ; p>.05$; $\left.\boldsymbol{\eta}^{2}=0.004\right]$, study $[F(2,477)=0,64 ; p>.05$; $\left.\boldsymbol{\eta}^{2}=0.003\right]$ and institutional $[F(2,477)=0,029$; $\left.p>.05 ; \boldsymbol{\eta}^{2}=0.0001\right]$ dimensions. Neither was there any difference in the total mean QVA score $\left(p=.029 ; p>.05 ;^{2}=.0001\right)$. No significant correlations were observed between the dimensions and the number of valid responses in the tasks with syllogisms.

\section{Results Obtained to Questions about the Task and Academic Life}

As far as experience with the task and the assessment of the task difficulty are concerned, there were no significant differences between the means in the three evaluative content groups $[F$ $(2,477)=0.46 ; p>.05 ;{ }^{2}=0.02 ; F(2,477)=$ $2.92 ; p>.05 ; \boldsymbol{\eta}^{2}=0.12$, respectively]. In the as- sessment of the difficulty of the task, the level of significance was very close to $0.05(p=.052)$, and the lowest mean obtained in this assessment was that of the neutral group and the highest mean that of the depreciative group. There was a significant difference between the sexes in relation to their experience with the task $[t(478)=$ $2.56 ; p<.05 ; d=0.25]$ and in the assessment of the task difficulty $[t(478)=3,07 ; p<.005 ; d=$ $0.3]$. Men had higher means $(M=2.27 ; S D=$ $0.99)$ than women $(M=2.03 ; S D=0.93)$ in their experience with the task and lower $(M=1.68$; $S D=0.78)$ than women $(M=1.91 ; S D=0.77)$ with regard to their assessment of the difficulty of the task.

On the other hand, in the question relating to their assessment of the application of the evaluative content to psychologists, there was a significant difference $[t(318)=9.32 ; p<.001 ; d=$ 1.05] between the means of agreements in the appreciative and depreciative content groups $(M$ = 2.64; $S D=0.60 ; M=1.99 ; S D=0.64$, respectively). As expected, the difference between the means reflected greater agreement with the laudatory content of the appreciative content group.

As for the question regarding affective involvement with the task, there was no significant difference $[t(318)=0.193 ; p>.05 ; d=0.02]$ be- 
tween the means of the appreciative and depreciative content groups $(M=2.6 ; S D=0.84 ; M=2.62$; $S D=1.02$, respectively) and there was no significant difference $[t(318)=0.39 ; p>.05 ; d=0.04]$ between the means of the females and males $(M$ $=2.62 ; S D=0.9 ; M=2.58 ; S D=0.98$, respectively). Finally, there was a weak positive correlation between the number of valid responses and the experience with the task $(N=480 ; r=$ $0.18 ; p>.001)$.

In the open question that sought to obtain additional information about university life, the majority $(68.3 \%)$ of the participants did not reply to it; of those who did, $12 \%$ reported dissatisfaction with the content of the subjects, with the curriculum and / or with their teachers and colleagues, among other things; $8 \%$ reported positive aspects, such as satisfaction with the course; $7.7 \%$ reported personal difficulties, or study and work overload; $1.3 \%$ mentioned that they did not know if they wanted to continue on the course, and $2.7 \%$ mentioned other aspects of university life.

Finally, with regard to the participants' opinion of the task, asked by way of an optional open question, of the $71 \%$ who replied to it, $36.8 \%$ considered it to be interesting, productive and / or they mentioned they were interested in the results of the study, considering that it led them to reflect on the profession; $10.8 \%$ emphasized the difficulty they felt in evaluating true and false premises, while $5.4 \%$ of these mentioned, either directly or indirectly, the conflict between the logic and content of the syllogisms; $7.3 \%$ considered the task easy and / or pleasurable; $6.7 \%$ reported not having properly understood the objectives and / or the initial difficulty of the task that was soon overcome; $6.1 \%$ found the task to be difficult and / or ambiguous; $2.3 \%$ considered the text to be exaggerated, but intentionally so, and $2.1 \%$ expressed other opinions. So most of the participants stressed the positive aspects of the task.

\section{Discussion}

As far as concerns the effect of the 'sex' variable on syllogistic reasoning, as mentioned, in the depreciative content groups, female stu- dents were significantly more sensitive to this content, although their performance was similar to that of the male students in the neutral content groups.

First of all these results indicate that depreciative evaluative content relating to the education and activities of psychologists has a negative effect in psychology students on their performance of logical tasks that involve syllogisms, especially in females. The results also suggest that the latter are more sensitive than men to the effects of depreciative statements regarding their education and future professional activities, although they perform similarly to men in tasks with syllogisms that have neutral content.

Although no significant differences were found between males and females in the appreciative content groups, and even though the size of the effect for comparison purposes is considered to be small ( $d=0.3$ ) as we saw, proximity to the significance index $(p=0.053)$ suggests that it would be interesting for future studies to clarify whether men, unlike women, might benefit from appreciative evaluative content related to their future profession.

In some studies that address differences between men and women in moral reasoning (Friesdorf, Conway, \& Gawronski, 2015), and emotional competence (Day \& Carroll, 2004), the results suggest that women prove to be more empathic to the problems and characters related in the tasks, thus manifesting greater emotional competence when assessing situations involving interpersonal conflict. As was observed, in the regulation of emotions, the greater use of rumination strategies in women (Nolen-Hoeksema \& Jackson, 2001) would tend to divert attention towards negative feelings, which might partly explain the results found.

However, in various pieces of work (Blanch \& Leese, 2011; Jung et al., 2014; Lefford, 1946) there are reports of more pronounced effects of negative affective content on performing reasoning tasks, which corroborates the results found here, especially with regard to the performance of female students.

As for the impact of the syllogisms on performance, we observed that the best perfor- 
mance for the whole sample occurred with " $\mathrm{Mo}$ dus Ponens", followed by "Affirming the Consequent" and "Denying the Antecedent", and the worst performance with "Modus Tollens". However, when the evaluative content is taken into account, there is a significant decrease in performance among women but not among men in syllogistic tasks related to "Modus Ponens" and "Denying the Antecedent" in the group with depreciative content.

With regard to these results, on the one hand, a decrease in performance in "Denying the Antecedent" might be expected, because this type of logically invalid syllogism is considered difficult and more likely to be influenced by the beliefs and expectations of the individuals and by the affective tonality of the content, as pointed out by studies in the area (e.g. Blanchette \& Leese, 2011). On the other hand, it may seem surprising to note the decrease in valid responses in the performance in the "Modus Ponens", a form of syllogism that is considered to be the easiest and most direct. It is possible that this result is due to the rejection of the strong association between the premises in women in the depreciative content group. As De Jong and Vroling (2014) observe, "Modus Ponens" is usually affected when such a reaction occurs. It can also be assumed that depreciative statements about the psychology course and the education of psychologists that are presented in a more direct way, with a strong association of ideas, may have had a role to play in this result.

Regarding the results found in the QVA-r, the score over 3 , which suggests good academic integration in both sexes, was also obtained in other Brazilian studies (Igue et al., 2008; Lamas et al., 2014, Sarriera et al., 2012, Schleigh, 2006, among others), two of them carrying out their research only with psychology students (Igue et al., 2008; Sarriera et al., 2012).

The highest academic satisfaction / integration mean occurred in the "career" dimension and the lowest in the "personal" dimension, which was also observed in the studies mentioned above. In fact, the highest satisfaction / integration mean in the 'career' dimension in the QVA- $r$ in university students is emphasized in these and in other studies (e.g. Granado et al., 2005), which suggests that confidence in the choice of course and career prospects are relevant factors for academic integration. In general, the means of the QVA-r dimensions observed in this study were lower than those found in the studies cited above. However, in the study developed here, only psychology students from different public universities participated, in contrast to the sample in other studies.

Research on the subject (Chee, Pino, \& Smith, 2005; Tessema et al., 2012) points to the fact that women find greatest academic satisfaction and are happiest with the curriculum. On the other hand, studies like that by Schleigh (2006) with Brazilian students, and by Monteiro and Gonçalves (2011), with Portuguese students, found that men were more satisfied with their higher education. However, these studies do not refer specifically to psychology students. In the above-mentioned studies, which were carried out only with psychology students, the differences between men and women was not a highlight of the research. There were no significant differences in the present study between the means of academic integration of each of the five dimensions and the total mean score in the QVA-r in the evaluative content groups, neither were any significant correlations observed between the dimensions and the number of valid responses in the tasks with syllogisms.

The expectation that differences in the affective sphere and / or in engagement with studies and with the positive career vision as expressed in the QVA-r, such as those observed in women and men, might be related to the number of valid responses, considering the three evaluative content groups, was not confirmed. On the other hand, these results seem to suggest that the depreciative tonality per se of the content related to the course and the professional formation of the students had a clear influence on student performance, especially the performance of women, which corroborates the idea that this content can negatively affect performance regardless of its relationship with the affective 
states and / or the academic experiences that are reported.

In issues that relate to the task, as we have seen, there were no significant differences between the sexes in the degree of involvement with the task and with the assessment of the application of the evaluative content to the course and to the profession. Differences were found only in the experience with the task, which was greater in men, and in the assessment of its difficulty, which was greater among women. So, male students reported greater familiarity with syllogisms and, consequently, found the task easier than female students, although these results did not have any influence on the performance of the task when the neutral, appreciative and depreciative content groups are taken into consideration.

In the open questions about university life in general, although most of the participants did not respond to this question, we found more complaints and reports of difficulties in those who responded to it than mention of academic satisfaction, a report that, in a way, contrasts with the general QVA-r score which, in its turn, suggests satisfactory academic integration. However, some of these reports of dissatisfaction refer to aspects not contemplated in the questionnaire, such as the relationship with teachers and the adequacy of the content of the subjects studied and the curriculum.

With regard to the participants' opinion about the task, its positive aspects were emphasized by those who answered the optional question. In this context, it was interesting to observe that some of the participants mentioned the intentional conflict between the logic and the tonality of the content, thus perceiving the nature of the task, but this was mentioned by an insignificant number of participants. This leads us to suppose that the majority of the participants did not perceive the conflict between the logical validity of the tasks and the professional beliefs and expectations that counterbalanced the negative statements made. Thus, despite the discomfort reported by a small number of individuals, especially those who saw the stories and depreciative content, this conflict seems to have been implicit in most of the participants, as suggested by the reports of some participants when they were asked their opinion about the task and whether it mobilized them affectively, which is coherent with results of studies in the area (Blanchette \& Amato, 2014; Blanchette \& Leese, 2011; Klauer \& Singmann, 2013), which to a certain extent, corroborate the idea of the prevalence of implicit heuristic processes associated with System 1 of Kahneman's model (2003), when there is a conflict between logic and emotion. This issue, however, deserves further clarification in complementary studies that use verbal protocols or other self-reporting instruments that can bring more information in this regard.

\section{Final Considerations}

The results of the research carried out here can make relevant contributions to our understanding of the influence of the evaluative content of problem statements when performing logical tasks that involve deductive reasoning, especially content related to the education and professional activities of university students. In this context, these results can help encourage debate on questions as yet unanswered by studies that investigate the effects of affectivity, in its multiple expressions, on human deductive reasoning.

We also conclude that the effects of evaluative content in deductive reasoning seem to occur more implicitly, as usually happens with other affective content and with interference in beliefs and expectations, in other words, these effects do not seem to depend on any explicit mediation of affective states and / or the perception of individuals in their performance of logical tasks, such as those proposed in this study.

The influence per se of this content on reasoning is also observed in these results, since they were not boosted by the degree of academic integration of the students, in other words, by their career prospects, engagement in studies and differences in the personal sphere, as reported in the QVA-r that was applied. 
There is also a need for future research that better clarifies whether the differences found between men and women also occur in other undergraduate courses where there is no female prevalence, as there is on the psychology course. The limits of the study here carried out also refer to its future developments, particularly those that refer to expanding the nature of the investigation to include other undergraduate courses in the biological and technological areas, and groups of individuals of other age groups and with different degrees of schooling.

Finally, we believe that these results may be of particular relevance to the academic context, since the problem situations experienced by the students in the university may have evaluative content that can influence performance in problem solving and in deductive reasoning processes, as well as in other human inferential processes.

\section{References}

Almeida, S. L., Soares, A. P., \& Ferreira, J. A. (2001). Adaptação, rendimento edesenvolvimento dos estudantes no ensino superior: Construção do Questionário de Vivências Acadêmicas. Methodus, 3-20.

Blanchette, I. (2014). Does emotion affect reasoning? Yes, in multiple ways. In I. Blanchette (Ed.), Emotion and reasoning (pp. 1-21). New York: Psychology Press.

Blanchette, I., \& Amato, J. N. (2014). Reasoning and emotion in the body. In I. Blanchette (Ed.), Emotion and reasoning (pp. 119-133). New York: Psychology Press.

Blanchette, I., \& Caparos, S. (2013). When emotions improve reasoning: The possible roles of relevance and utility. Thinking \& Reasoning, 19(34). doi: 10.1080/13546783.2013.791642

Blanchette, I., \& Campbell, M. (2012). Reasoning about highly emotional topics: Syllogistic reasoning in a group of war veterans. Journal of Cognitive Psychology, 24, 157-164.

Blanchette, I., \& Leese, J. (2011). The effect of negative emotion on deductive reasoning: Examining the contribution of physiological arousal. Experimental Psychology, 58(3), 235-246.
Blanchette, I., Lindsay, P., \& Davies, S. (2014). Intense emotional experiences and logicality: An exploration of deductive reasoning in survivors of sexual abuse. The Psychological Record, 64(4), 859-867.

Blanchette, I., \& Richards, A. (2010). The influence of affect on higher level cognition: A review of research on interpretation, judgement, decision making and reasoning. Cognition \& Emotion, 24(4), 561-595.

Blanchette, I., Richards, A., Melnyk, L., \& Lavda, A. (2007). Reasoning about emotional contents following shocking terrorist attacks: A tale of three cities. Journal of Experimental Psychology: Applied, 13, 47-56.

Boden, M. T., \& Barenbaum, H. (2010). The bidirectional relations between affect and belief. Review of General Psychology, 14, 227-239.

Brody, L. R., \& Hall, J.A. (2008). Gender and emotion in context. In M. Lewis, J. M. Haviland-Jones, \& L. F. Barret (Eds.), Handbook of emotions (pp. 395-404). New York: The Guilford Press.

Chee, K. H., Pino, N. W., \& Smith, W. L. (2005). Gender differences in the academic ethic and academic achievement. College Student Journal, 39(3), 604-618.

Day, A. L., \& Carroll, S. A. (2004). Using an ability-based measure of emotional intelligence to predict individual performance, group performance, and group citizenship behaviors. Personality and Individual Differences, 36, 1443-1458.

De Jong, P., \& Vroling, M. (2014). Better safe than sorry: Threat-confirming reasoning bias in anxiety disorders. In I. Blanchette (Ed.), Emotion and reasoning (pp. 22-43). New York: Psychology Press.

De Neys, W. (2012). Bias and conflict: A case for logical intuitions. Perspectives on Psychological Sciences, 7, 28-38.

De Neys, W. (2014). Conflict, arousal, and logical gut feelings. In I. Blanchette (Ed.), Emotion and reasoning (pp. 22-43). New York: Psychology Press.

Eliades, M., Mansell, W., Stewart, A. J., \& Blanchette, I. (2012). An investigation of belief-bias and logicality on reasoning with emotional contents. Thinking \& Reasoning, 18(4), 461-479.

Evans, J. S. T. (2008). Dual-Processing accounts of reasoning, judgment, and social cognition. 
Annual, Review of Psychology, 59, 255-278. doi: 10.1146/annurev.psycho.59.103006.093629

Friesdorf, R., Conway, P., \& Gawronski, B. (2015). Gender differences in responses to moral dilemmas: A process dissociation analysis. Personality and Social Psychology Bulletin, 41(5), 696-713.

Gangemi, A., Mancini, F., \& Johnson-Laird, P. N. (2013). Models and cognitive change in psychopathology. Journal of Cognitive Psychology, 25(2), 131-138.

Granado, J. I. F. (2004). Vivência acadêmica de universitários brasileiros: Um estudo de validade e precisão do QVA-r (Master thesis, Programa de Estudos de Pós-Graduação em Psicologia, Universidade de São Francisco, São Paulo, SP, Brazil).

Granado, J. I. F., Santos, A. A. A., L. S., Almeida, L. S., Soares, A. P., \& Guisande, M. A. (2005). Integração acadêmica de estudantes universitários: Contributos para a adaptação e validação do QVA-r no Brasil. Psicologia e Educação, 4(2), 31-41.

Igue, E. A., Bariani, I. C. D., \& Milanesi, P. V. B. (2008). Vivência acadêmica e expectativas de universitários ingressantes e concluintes. PsicoUSF, 13(2), 155-164.

Johnson-Laird, P. N., Khemlani, S. S., \& Goodwin, G. P (2015). Logic, probability, and human reasoning. Trends in Cognitive Science, 20, $1-14$

Jung, N., Wranke, C., Hamburger, K., \& Knauff, M. (2014). How emotions affect logical reasoning: Evidence from experiments with mood-manipulated participant, spider phobics, and people with exam anxiety. Frontiers in Psychology, 5, $1-12$.

Kahneman, D. (2003). A perspective on judgment and choice: Mapping bounded rationality. American Psychologist, 58(9), 697-720.

Kahneman, D., \& Frederick, S. (2005). A model of heuristic judgment. In K. J. Holyoak \& R. G. Morrison (Eds.), The Cambridge handbook of thinking and reasoning (pp. 267-293), Cambridge, MA: Cambridge University Press.

Klauer, K. C., \& Singmann, H. (2013). Does logic feel good? Testing for intuitive detection of logicality in syllogistic reasoning. Journal of Experimental Psychology: Learning, Memory, and Cognition, 39(4), 1265-1273. doi: 10.1037/ a0030530.

Lamas, K. C. A., Ambiel, R. A. M., \& Silva, B. T. A. O. L. (2014). Vivências acadêmicas e empregabilidade de universitários de final de curso. Temas de Psicologia, 22(2), 61-72.

Lefford, J. S. (1946). The influence of emotional subject matter on logical reasoning. Journal of General Psychology, 34, 127-151.

Melton, R. J. (1995). The role of positive affect in syllogism performance. Personality \& Social Psychology Bulletin, 21, 788-794.

Monteiro, A. M., \& Gonçalves, C. M. (2011). Desenvolvimento vocacional no ensino superior: Satisfação com a formação e desempenho acadêmico. Revista Brasileira de Orientação Profissional, 12(1), 15-27.

Nicolle, A., \& Goel, V. (2014). What is the role of ventromedial prefrontal cortex in emotional influences on reason? In I. Blanchette (Ed.), Emotion and reasoning (pp. 154-173). New York: Psychology Press.

Nolen-Hoeksema, S., \& Jackson, B. (2001). Mediators of gender differences in rumination. Psychology of Women Quarterly, 25, 37-47.

Santos, A. A. A., Noronha, A. P. P., Amaro, C. B., \& Villar, J. (2005). Questionário de vivência acadêmica: Estudo de consistência interna do instrumento no contexto brasileiro. In M. C. R. A., Joly, A. A. A. Santos, \& F. F. Sisto (Eds.), Questões do cotidiano universitário (pp. 159178). São Paulo, SP: Casa do Psicólogo.

Sarriera, J. C., Paradiso, A. C., Schutz, F. S., \& Howes, G. P. (2012). Estudo comparativo da integração ao contexto universitário entre estudantes de diferentes instituições. Revista Brasileira de Orientação Profissional, 13(2), 163-172.

Schleigh, A. L. R. (2006). Integração à educação superior e satisfação acadêmica de estudantes ingressantes e concluintes: Um estudo sobre relações (Master thesis, Universidade Estadual de Campinas, SP, Brazil).

Schleigh, A. L. R., Polydoro, S. A., \& Santos, A. A. A. (2006). Escala de satisfação com a experiência acadêmica de estudantes do ensino superior. Avaliação Psicológica, 5(1), 11-20.

Soares, A. B., Francischetto, V., Dutra, B. M., Miranda, J. M., Nogueira, C. C. C., Leme, V. R., ...Almeida, L. S. (2014). O impacto das 
expectativas na adaptação acadêmica dos estudantes no Ensino Superior. Psico-USF, 19(1), 49-60.

Stanovich, K. E., \& West, R. (2002). Individual differences in reasoning: Implications for the rationality debate? In T. Gilovich, D. Griffin, \& D. Kahneman (Eds.), Heuristics \& biases: The psychology of intuitive judgment (pp. 421-440). New York: Cambridge University Press.

Tessema, M. T., Ready, K., \& Yu, W. (2012) Factors affecting college students' satisfaction with major curriculum: Evidence from nine years of data. International Journal of Humanities and Social Science, 2(2), 34-44.
Tversky, A., \& Kahneman, D. (1983). Extensional versus intuitive reasoning: The conjunction fallacy in probability judgment. Psychological Review, 90(4), 293-315.
Received: 05/10/2016

$1^{\text {st }}$ revision: $16 / 05 / 2017$

Accepted: 18/05/2017 distribution, and reproduction in any medium, provided you give appropriate credit to the original author(s) and the source, provide a link to the Creative Commons license, and indicate if changes were made. 